\title{
KAJIAN ESTETIKA PAMOR KERIS KAMARDIKAN
}

\author{
Febrian Wisnu Adi *)
}

\begin{abstract}
The aim of this research is to be searched about aesthetic and historical background that includes the shape, meaning, and function as well as the factors that underlie Pamor keris kamardikan in Surakarta. The analysis of the Pamor keris kamardikan Surakarta is not a simple matter. The question such as: what Pamor keris kamardikan is; why it had been created; when it start created; whose the man behind of created; where place that Pamor keris kamardikan has been exsist; and how about the histocal about it. Change of palace culture maybe happen to the progresive culture with any perception. It can be indicated like social criticism movement in postmodern age, such as: happening art, environmental art, etc.

While the factors underlie the similarities and differences are the internal and external factors. The Internal factors are the rules and policy stated by the actor in this regions. The external factor is the factor happens because the society social condition that is more developed as well as the policy of the government of Republic of Indonesia in the tourism sector.

The method used in the research is qualitative research with multidicipline approach focusing on the study of art. Aesthetic approach is used for relating the style of art. This approach is used with other approaches and use the relevant teories such as: history, communication, anthropology, archeology, and sociology.

This research has conelude that movemen of Pamor keris kamardikan Surakarta is in the structure or style. Historical background of movement started on 1970 in case of many keris artist in Surakarta created it with many purposed, basicly, Pamor keris Kamardikan Surakarta have two poin of movement, there are an aesthetic.
\end{abstract}

Keyword: Pamor keris, kamardikan, aesthetic.

\section{PENDAHULUAN}

Kemajuan estetika bentuk keris mengalami masa keemasan pada masa kerajaan Mataram Islam. Zaman Mataram Islam merupakan masa sebelum terjadinya Perjanjian Giyanti 1755. Perjanjian Giyanti menyebabkan terjadinya pembagian wilayah Mataram Islam menjadi dua, yaitu Surakarta dan Yogyakarta. Kedua daerah ini meskipun berasal dari satu kerajaan memiliki perbedaan dalam perkembangannya. Perbedaan itu terutama terdapat dalam tata cara dan kesenian kraton, akan tetapi dalam perkerisan dapat dikatakan secorak.

Keris pada masa lampau merupakan simbol supremasi orang Jawa, terutama kaum pria. Tidak sembarang orang dapat memilikinya. Keris tidak jarang identik dengan adidaya atau kanuragan sebagai

\footnotetext{
* Febrian Wisnu Adi (wisnu_adi@yahoo.com), Staf Pengajar Jurusan Kriya Fakultas seni Rupa Institut Seni Indonesia Yogyakarta
} 
penunjuk eksistensi seseorang dalam strata sosial di lingkungan masyarakatnya.

Simbol memegang peranan penting dalam dalam tingkah laku manusia. Tingkah laku manusia dalam berbagai hal tergantung dalam penggunaan simbol. Simbol adalah suatu yang maknanya diberikan oleh yang menggunakan simbol. Simbol dapat dibentuk benda-benda, warna, suara, atau gerak suatu benda. Simbol yang diberikan manusia penggunaannya berdasar pada aspek fisik atau ditentukan oleh unsur-unsur intrinsik di dalam bentuk fisiknya. Namun demikian, yang membedakan manusia dengan binatang adalah penggunaan simbol dalam tingkah lakunya (Leslie A. White, 1949).

Aspek simbolik telah mewarnai pandangan masyarakat terhadap metalurgi. Sampai pada masa pengaruh kebudayaan India di Jawa, aspek-aspek simbolik masih tampak pada teknik pembuatan artefak. Terlebih lagi keris sebagai artefak ideoteknik. (Timbul Haryono, 2008:72-73). Simbol sendiri berkaitan erat dengan pamor atau gambar-gambar pada bilahan keris. Jika kata pamor dikenakan pada orang, artinya mempunyai wajah yang baik atau cantik, pamor pada bilah keris ada yang timbul karena disengaja, ada pula yang timbul secara kebetulan. Pamor yang timbul secara kebetulan disebabkan oleh proses pencampuran besi bahan bilah keris yang setelah dibentuk menjadi bilah, maka timbul gambar-gambar. Pamor merupakan bagian keris yang sangat penting. Sebab menurut kepercayaan masyarakat, pamor mempunyai daya magis yang sangat besar dan mempengaruhi kehidupan si pemilik. Pengaruh tersebut tidak sama antara pamor satu dengan lainya, dan nama corak pamor sampai beratus-ratus. Daya magis atau daya keramatnya pun berbeda-beda.
Berbicara tentang keris tidak bisa lepas dari pamor. Pamor merupakan hiasan atau motif atau ornamen yang berbentuk abstrak atau dekoratif yang terdapat pada bilah tosan aji (Keris, Tombak, Pedang atau Wedung dan lainnya). Hiasan ini dibentuk bukan karena diukir atau diserasah (Inlay) atau dilapis tetapi karena teknik tempaan yang menyatukan beberapa unsur logam yang berlainan.

Teknik tempa ini sampai saat ini hanya dikuasai oleh para Empu dari wilayah Nusantara dan sekitarnya saja (Malaysia, Brunei, Philipina dan Thailand).

Diluar wilayah Nusantara dan sekitarnya biasanya hanya dikenal teknik Inlay saja seperti pedang dari Iran, atau negara Eropa lainnya sehingga walau secara seni (art) tampak indah tetapi kesan “Angkernya”kurang.

Pedang buatan pandai besi di Damascus juga mempunyai Pamor, namun pamor yang dihasilkan tidak ada unsur kesengajaan dalam membuat pamor, dikarenakan unsur besi yang ditempa sudah tercampur dengan beberapa unsur logam yang mengakibatkan timbulnya pamor, Teknik tempa menjadi dasar Empu di wilayah Nusantara (Khususnya Jawa) dengan teknik pencampuran besi, baja, nikel sehingga terbentuk pamor yang indah dan bernilai seni tinggi.

\section{MENGENAL MATERIAL PAMOR KERIS KAMARDIKAN}

Seiring dengan perkembangan zaman dan berjalannya waktu, UNESCO mengakui keris sebagai warisan budaya dunia pada tahun 2005, dan mengukuhkan keris sebagai Masterpiece of the Oral and Intangible Heritage of Humanity. Tidak dapat dipungkiri bahwa keris merupakan mahakarya yang menyimpan rahasia hidup 
di dalamnya. Keris adalah ilmu sinengker atau ilmu yang dirahasiakan karena aris dari kata keris berarti ada rahasia yang dipendam di dalamnya. Rahasia tersebut adalah falsafah Jawa, dan rahasia falsafah kehidupan yang terkandung di dalam keris belum banyak diketahui. Keris bukan sekedar senjata tajam, melainkan sejatinya adalah senjata untuk memerangi diri sendiri dari belenggu nafsu duniawi. Dalam keris tersirat simbolisasi hidup yang baik, sesuai etika, norma, agama, dan negara. Keris secara umum mempunyai arti khusus yang diagungkan. Pengetahuan tentang keris sangat luas, terutama menyangkut aspek mistis, filosofis, fungsi sosial, tradisi, dan seni rupa. Nilai keris sangat berarti karena adanya budaya pengagungan yang awalnya bersumber dari kekuasaan atau kraton. Namun demikian, nilai keris sekarang telah terkikis oleh pandangan modern seiring dengan perkembangan kebudayaan dan sistem kehidupan sosial. Bentuk dan fungsi keris mengalami perkembangan dan perubahan. Keris yang pada awalnya berbentuk sederhana, kemudian mengalami perubahan sekitar abad XIV menjadi bentuk keris sekarang dengan hiasan yang bagus. Fungsi keris juga mengalami perubahanperubahan, keris yang pada awalnya berfungsi sebagai senjata, kemudian menjadi barang keramat yang dihormati, pusaka yang dipuja, sebagai kelengkapan berpakaian, baik raja maupun rakyat jelata, lambang ikatan keluarga, tanda jasa, tanda pangkat atau jabatan, lambang prestige, barang mewah, dan akhirnya dianggap sebagai benda seni atau cenderamata (Soekiman, 1983:9-10).

Perkembangan teknologi dan pariwisata pada era globalisasi secara tak langsung melahirkan kontinuitas dan perubahan, termasuk dalam bidang penciptaan keris. Pada awal tahun 70-an muncul periode keris yang bernama keris kamardikan. Keris kamardikan merupakan periodisasi keris yang berkembang setelah masa penjajahan dan hegemoni kerajaan di Surakarta. Perajin-perajin keris Surakarta yang selanjutnya tidak bersedia disebut sebagai empu, seperti Yohanes Yantono, Sukamdi, K.R.T. Subandi Suponingrat, Joko Suryana, dan Basuki Teguh Yuwana merupakan pelopor munculnya keris kamardikan. Bentuk keris dan pamor juga mengalami perkembangan seperti inovasi atau pembaharuan bentuk.

Berbicara tentang keris tidak terlepas dari pamor, Pamor Adalah sebuah bentuk ilustrasi atau gambar yang muncul dipermukaan bilah keris yang merupakan hasil evolusi-progresif dari Empu dan para pande besi. Mereka melakukan mixing atas berbagai jenis logam, seperti besi, baja, nikel dan logam lain. Paham dengan kelemahan masing-masing logam, maka para empu membuat percobaan mencampur berbagai jenis logam untuk menghasilkan pamor yang unggul dari sisi material.

Baja yang keras, tajam, namun getas (mudah patah), diapit oleh logam lain yang lentur (seperti lapisan besi lunak dan nikel) untuk menutupi kelemahan baja yang keras dan mudah patah tersebut. Karena susunan berlapis itu keris memiliki keistimewaan lain, lapisan besi lunak dan nikel menimbulkan konfigurasi yang indah dan itulah yang disebut 'pamor'. Kata 'pamor' berasal dari bahasa Jawa 'amor' atau 'diwor' yang artinya 'dicampur' atau 'disatukan'. (Kutipan: A.Ardiasto). 


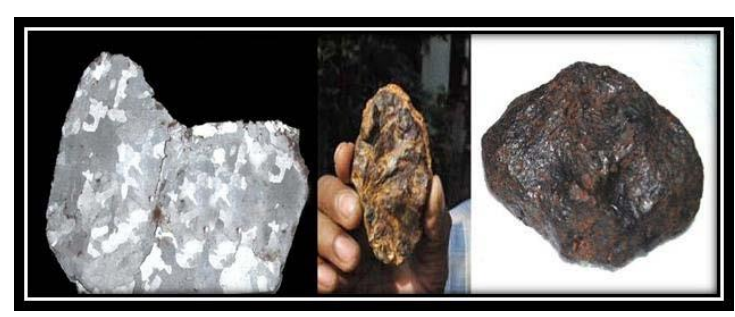

Gb. 1. (Foto: Repro www.javakeris.com) Batu Meteor adalah material yang paling utama dalam pembuatan pamor keris

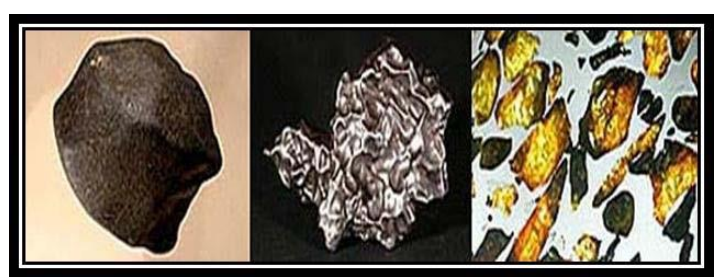

Gb. 2. (Foto: Repro www.javakeris.com) Stones meteorite - Irons meteorite - penampang irisan Stony irons meteorite

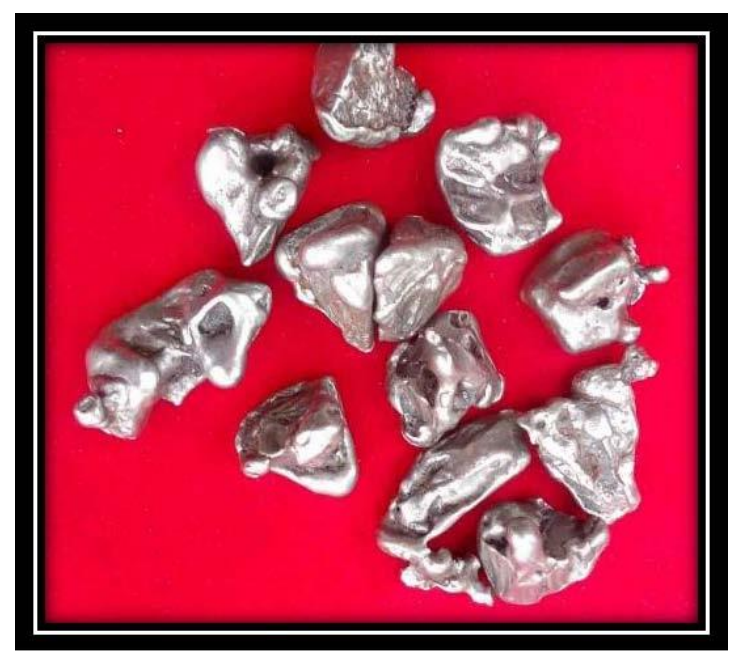

Gb. 3. (Foto: Repro www.javakeris.com)

Logam Nikel bahan dasar pembuat pamor keris

\section{TEKNIK PEMBUATAN PAMOR KERIS}

\section{KAMARDIKAN}

Banyak para ahli keris berbicara tentang keris pamor keris, namun sedikit yang memberi pengertian mengenai definisi tentang pamor keris. Hal ini perlu karena dalam masyarakat sering dijumpai pengertian yang keliru dan kerancuan mengenai apa yang disebut dengan pamor keris. (Pamungkas, 2007:22-28).

Pamor keris dibuat oleh seorang pandai besi yang lazim disebut empu dengan gam bar simbol abstrak yang mempunyai tujuan harapan atau doa untuk sang pemilik keris. Pada masa perkembangan dan pemerintahan kerajaan, seorang empu merupakan warga istana atau abdi (punggawa) di lingkungan istana. Hal ini dapat diasumsikan bahwa keris merupakan budaya istana. Keris-keris yang berkembang di istana berkembang mencapai puncak kualitasnya sebagai benda seni. Raja merupakan kreator, fasilitator, motivator, dinamisator, dan juga apresiator budaya keris pada saat itu. Perbandingan dengan pembuatan keris di luar istana saat itu bahwa keris yang di buat oleh masyarakat non-bangsawan cukup sulit mencapai mutu yang bagus karena berbagai kendala. Kendala tersebut antara lain: bahan baku, waktu, biaya, kemahiran, dedikasi, dan motivasi empu.

Keris pada zaman kemerdekaan sekarang ini, aturan dan ketentuan pembuatan keris dan pamornya tidak hanya ditentukan oleh keraton. Teknik pembuatan keris dan cara membuat pola pamornya sudah masuk ke dalam institusi pendidikan.

Mengenal tentang bentuk-bentuk pamor yang terdapat pada keris memang tidak mudah pertama-tama harus mengetahui tentang pola pamor keris pola pamor keris ada dua macam yaitu:

pamor mlumah, pamor miring. Dilihat dari cara pembuatannya pamor ada dua cara pembuatan Pamor yaitu Mlumah dan Miring. Pamor mlumah adalah pola pamor yang lapisan-lapisan pamornya mendatar sejajar dengan permukaan tosan aji pamor ini mudah dalam pembuatanya sedangkan pamor miring lapisan pamornya tegak lurus permukaan bilah adalah teknik yang susah dalam membuat pamor. 


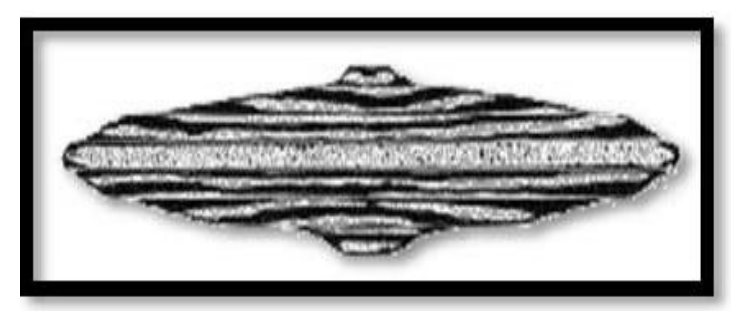

Gb. 4 Pamor mlumah

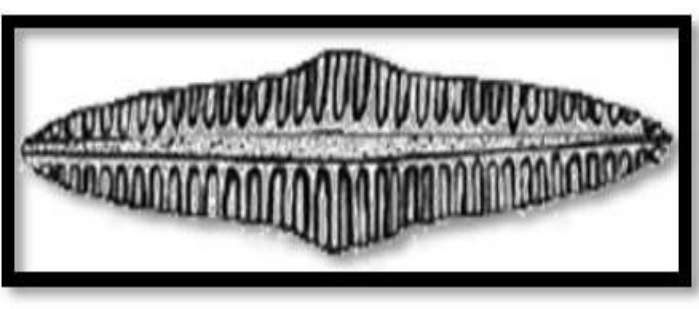

Gb.5 Pamor miring

Pamor Mlumah biasanya bermotif Beras Wutah, Ngulit Semangka, Satria Pinayungan, Udan Mas, Wulan-wulan dan sebagainya, sedangkan Pamor Miring umumnya motif Adeg, Batu Lapak, Sodo Saeler, Tumpuk dan lain sebagainya. Pamor Miring mempunyai tekstur agak kasar bila diraba bilahnya dan nyekrak (bergerigi tajam) lain halnya untuk pamor mlumah mempunyai tekstur yang halus bila diraba dengan jari.

Dalam proses pembuatan pamor miring maupun mlumah apabila dalam proses melipatanya tidak sempurna atau gagal, baik di pamor mlumah atau miring, maka hasilnya bisa menjadi pamor luluhan, pamor dan besi sudah menyatu walau tidak terlalu homogen, Pamor luluhan disebut juga dengan pamor nggajih (lemak) pamor yang dibuat mengalami kegagalan atau ketidak berhasilan dalam membuat pamor yang diinginkan sang empu.

Selain teknik pembuatan pamor miring dan pamor mlumah ada teknik yang dibuat dengan kombinasi pamor mlumah dan miring hanya saja pembuatannya sangat sulit, lebih sulit dari pembuatan pamor miring. Pada saat ini muncul teknik baru dalam membuat pamor yaitu teknik rekayasa atau titipan teknik ini muncul pada era keris kamardikan yang diterapkan pada keris-keris cinderamata dengan teknik pembuatan pamornya dengan cara mengoleskan, menuang bahan pamor ke bilah, bahan pamor yang digunakan adalah logam yang titik leburnya lebih rendah dari besi seperti timah putih, peuwter. Pamor ini berbentuk rangkaian kecil yang merupakan perlambang atau tuah tertentu dan pamor ini jarang berdiri sendiri, umumnya tergabung dengan pamor lain yang lebih dominan, antara lain Beras Wutah, Pulo Tirto atau Pendaringan Kebak. Pamor ini ada yang merupakan pamor tiban, tidak sengaja dibuat seperti Pamor Rahala, Dikiling, Inkal, Putri Kinurung, Gedong Mingkem, Jung Isi Dunya, Telaga Membleng dll. Pamor titipan yang merupakan pamor rekan antara lain yang terkenal adalah Kuto Mesir, Kul Buntet, Udan Mas, Watu Lapak. Pamor Titipan yang merupakan pamor tiban dibuat bersama dengan pamor lainnya sedangkan yang rekan biasanya dibuat setelah pamor dominan jadi, merupakan pamor yang disusulkan. (www.pdffactory.com).
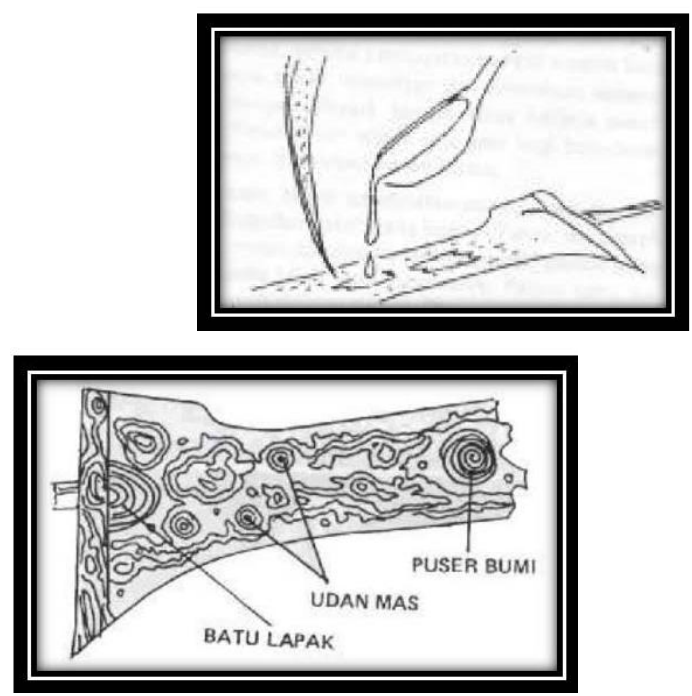

Gb.6 Gb.7 Merupakan Pamor Titipan atu Rekayasa (www.pdffactory.com) 


\section{KLASIFIKASI BENTUK PAMOR KERIS KAMARDIKAN}

Menurut klasifikasinya bentuk pamor dibedakan menjadi beberapa macam bentuk pamor antara lain :

1. Pamor Mrambut : kesan rabaannya terasa seperti meraba rambut, munculnya pamor dipermukaan bilah bagai serat-serat lembut dan halus dan biasanya terjadi di pamor Adeg terutama yang jenis pamor miring.

2. Pamor Nggajih : kesannya seperti berlemak, bagai lapisan lemak beku menempel dibilah.

3. Pamor Mbugisan : kesan penglihatan gradasi warna pamor tidak kontras. Batas antara tepi pamor dan bilah tidak terlalu nyata.

4. Pamor Sanak/Nyanak : kesan penglihatan dan rabaan tidak terlalu jelas, jadi gambar pamor tidak terlalu jelas dan kalau diraba juga tidak jelas.

5. Pamor Kelem : pamor cukup jelas tetapi perbedaan warna dan kecemerlangan pamor dengan warna besi tak terlalu nyata, rabaannya kurang kontras tapi juga bukan lumer.

6. Pamor Ngintip : kesan rabaannya kasar tetapi tidak tajam. Jika dibandingkan dengan lukisan seperti lukisan dengan menggunakan teknik palet.

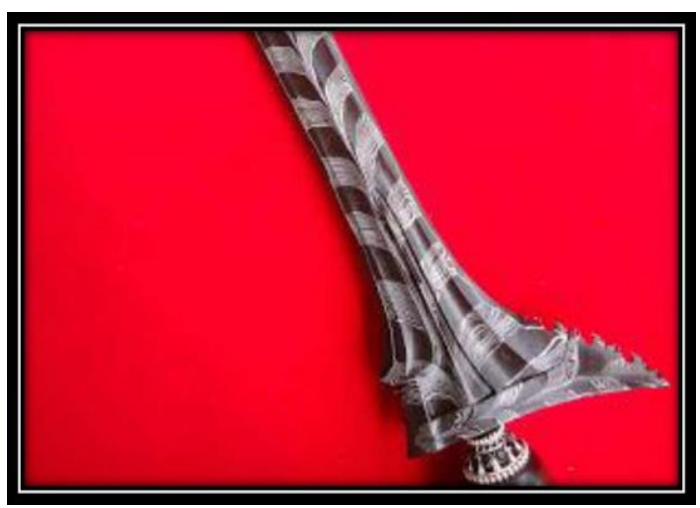

Gb.8. (Foto: Repro www. pamor+keris.com)

Pamor: Ron Genduru. (daun Palm) Tangguh ( Masa Pembuatan ) : Kamardikan

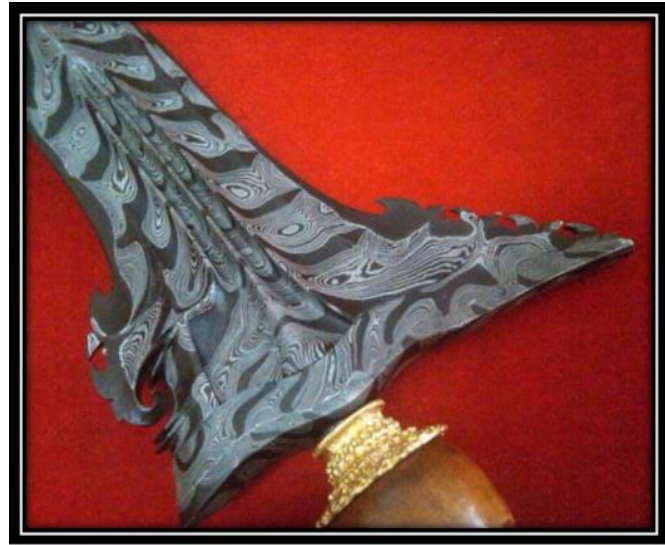

Gb. 9. (Foto: Repro www. pamor+keris.com) Pamor : Lar Gangsir Agal (Bulu Gangsir, Binatang seperti jangkrik tapi lebih besar) Tangguh ( Masa Pembuatan ) : Kamardikan

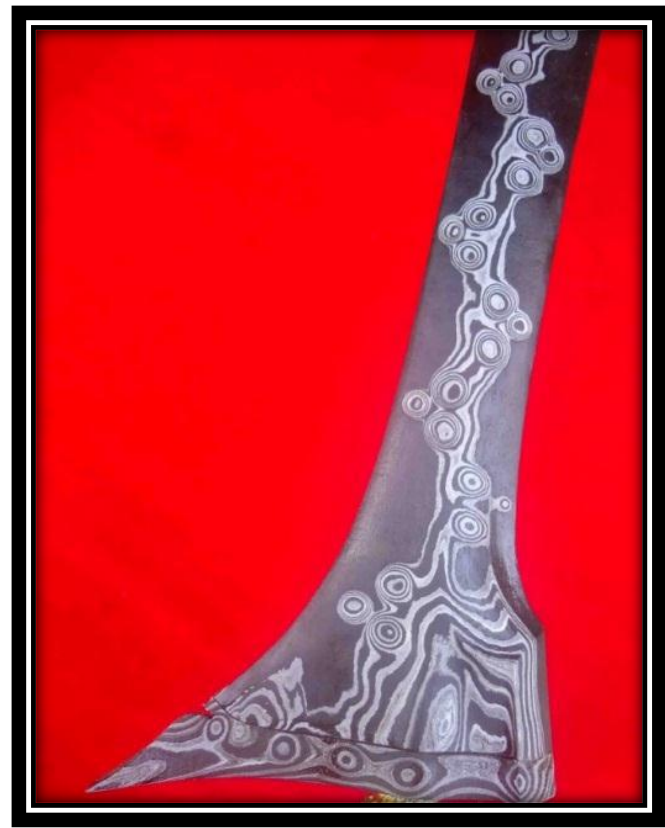

Gb. 10. (Foto: Repro www. pamor+keris.com)

Pamor : Sekar Kopi. Tangguh ( Masa Pembuatan ) : Kamardikan 


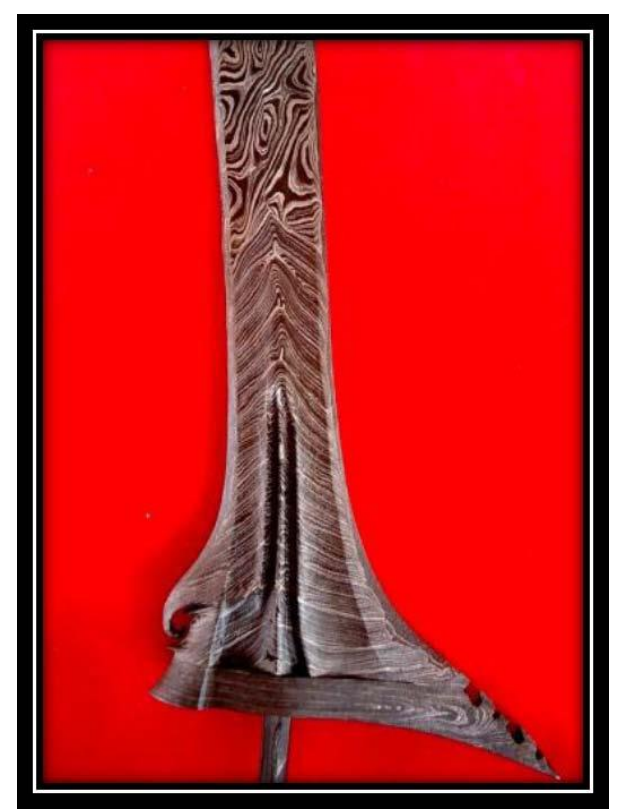

Gb. 11. (Foto: Repro www. pamor+keris.com) Pamor / Lambang / Filosofi : Tri Warno ( Junjung Drajat-Kenanga Ginubah-Toyo Mambeg ) Tangguh ( Masa Pembuatan ) : Kamardikan

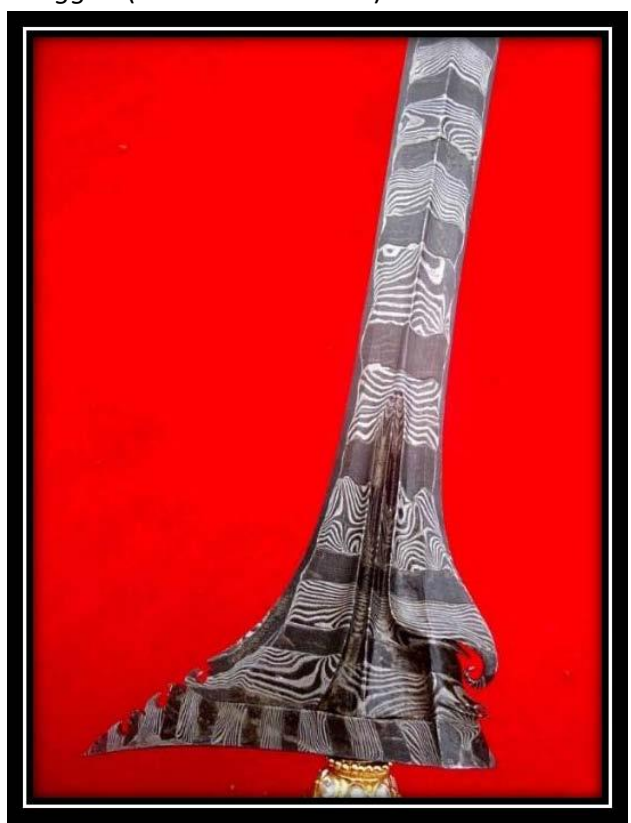

Gb. 12. (Foto: Repro www. pamor+keris.com) Pamor : Korowelang. Tangguh (Masa Pembuatan) : Kamardikan

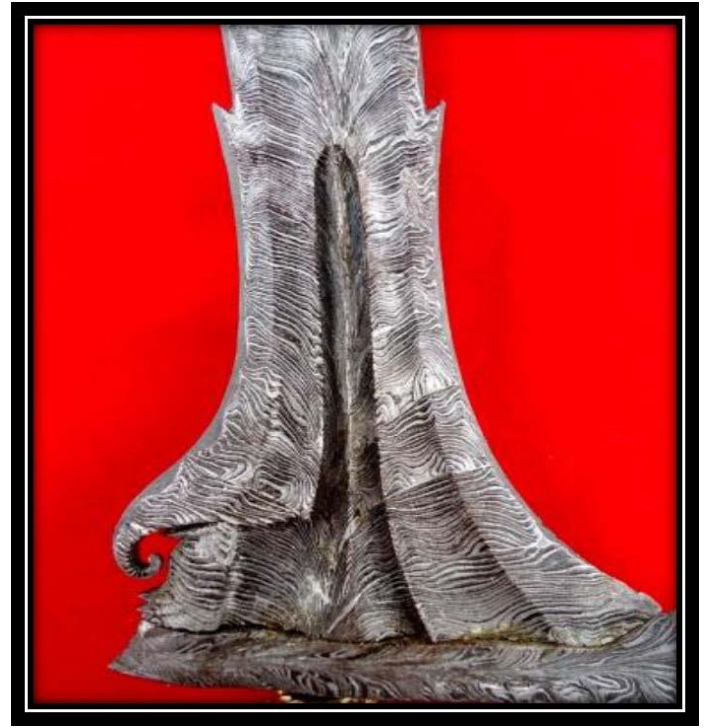

Gb. 13. (Foto: Repro www. pamor+keris.com) Pamor : Blarak Sineret (daun kelapa yang diseret). Tangguh ( Masa Pembuatan ) : Kamardikan

\section{KESIMPULAN}

Estetika Pamor Keris Kamardikan yang kontemporer mungkin saja tidak terikat lagi pada Pamor standar, karena akan lebih mengutamakan kebebasan dalam ekspresinya dari sekedar berfungsi sebagai gambar abstrak pada keris. Melalui pengetahuan tentang simbolisme keris itu, maka seni rupa pamor keris dapat berupa tanggapan terhadap nilai yang kompleks dari pamor kerisan itu sendiri, kecuali fungsi keris dalam tradisi busana.

Budaya tentang filosofi pamor keris yang berhubungan erat dengan sejarah dan tradisi yang bersumber dari kekuasan keraton tetap menjadi target konservasi. Sementara pamor keris Kamardikan kontemporer akan semakin terpengaruh perkembangannya karena diikuti penciptaan bentuk pamornya secara kreatif, sehingga akan mudah dinikmati oleh para awam keris. Seniman atau empu keris masa kini sudah cukup menguasai kaidah atau pakem karena sering mutrani (menduplikasi), tidak diragukan ketika dihadapkan dengan pamor keris-keris tua, karena pada hakekatnya 
penguasaan terhadap pakem dan pemahaman terhadap nilai-nilai tradisi keris tetap menjiwai para empu dalam berkarya (essensi).

Keris dan pamornya akan menjadi kaya aliran sebagai varian klasik dan sebagai karya kontemporer, bukan mati salah satunya, melainkan akan tumbuh dimasa mendatang sebagai sebuah bentuk pelestarian. Tingkat intelektual seniman keris kamardikan sertarta penciptaan Pamornya, sikap batin dan keinginannya mengutarakan suatu maksud (seperti filosofis, simbolis, reka inspirasi dan hal-hal esoteric lainnya) dalam 'penciptaan' karya, merupakan proses yang sama seperti pada 'proses penciptaan' Pamor keris tua oleh para empu keris zaman dahulu yaitu sekuensial essensinya sama tetapi beda kurun waktu penciptaannya.

Pergeseran budaya sentralistik keraton atau pengagungan, mungkin akan terjadi menuju budaya progresif dengan pemaknaan yang bebas. Hal ini diindikasikan seperti munculnya muatan kritik sosial pada era postmodernisme, seperti happening art, environ mental art, dan sebagainya. Perkembangan keris Kamardikan kontemporer tidak akan lepas dari tuntutan pemenuhan sisi ketertarikan, untuk beradaptasi dengan modernisasi, dan akan menjadi sebuah seni rupa yang baru lahir dari Nusantara.

Sudah merupakan hal yang biasa jika keris dianggap sebagai sebuah benda yang memiliki kekuatan mistik. Anggapan ini bahkan menjadi keyakinan oleh masyarakatnya, mereka percaya adanya kekuatan itu oleh karena empu menanamkan daya dari mantera atau doadoanya. Banyak diantara mereka menyimpan keris sebagai jimat dan diyakini membawa keberuntungan. Aspek mistik dalam dunia keris sangat menarik dibicarakan, walaupun bersifat subyektif, namun ada kalanya kekuatan itu bisa dirasa atau dilihat oleh banyak orang. Penciptaan keris dizaman dahulu selalu melalui prosesi yang berkaitan dengan ritual dan spiritual. Pada pamor keris Kamardikan hal ini belum dijamah. Namun Pamor pada keris Kamardikan belum tentu 'tidak memiliki' kekuatan gaib.

Selanjutnya, keris pamor kamardikan dihadapkan pada sebuah peluang sekaligus tantangan bahwa tak dapat dipungkiri diapresiasinya keris oleh para kolektor pisau dan senjata tajam internasional memaksa para empu untuk segera menentukan sikap demi menjamin kelangsungan hidup tradisi perkerisan sebagai ikon budaya adiluhung bangsa.

$$
\text { Apresiasi dunia internasional }
$$

terhadap keris akan memunculkan kerawanan atas Hak atas Kekayaan Intelektual (HaKI) mengingat beberapa kali kekayaan intelektual dan budaya bangsa ini diklaim secara sepihak oleh bangsa lain. Demikian pula, kekayaan tradisi perkerisan nusantara juga mulai dibajak di luar negeri, seperti hal-nya kita temukan pisau-pisau bermerk internasional asal Amerika yang menggunakan pola pamor yang tidak lain adalah pamor-pamor yang kita kenal sebagai lar gangsir, untu hiu yang sangat mirip dengan pamor untu walang, dan udan mas. Pendaftaran HaKI secara kolektif atas 400-an jenis dapur keris dan 160 ragam pamor mutlak harus segera dilakukan dan sebagai peninggalan budaya bangsa adalah kewajiban mutlak bagi pemerintah untuk melakukannya. 


\section{DAFTAR PUSTAKA}

A. White, Leslie The Science of Culture: $A$ Study of Man and Civilization. New York: Grove Press, Inc., 1949.

Hamzuri. Keris. Jakarta: Djambatan dan PT. Karya Unipress, 1988.

Haryono, Timbul. Logam dan Peradaban Manusia. Yogyakarta: MedPrint Offset, 2001.

Majalah PAMOR, Vol. 1,No. 3, Maret: 2007.

Pamungkas, Ragil. Mengenal Keris Senjata"Magis"Masyarakat Jawa. Yogyakarta: Narasi, 2007.

Soedarsono, R.M. Seni Pertunjukan Indonesia dan Pariwisata. Bandung, Masyarakat Seni Pertunjukan Indonesia, 1999.

Soekiman, Djoko, Keris: Sejarah Dan Fungsinya. Yogyakarta: Javanologi, 1983. 